Technological University Dublin

ARROW@TU Dublin

2010-01-01

\title{
Corrosion Protection of AA 2024-T3 Aluminium Alloys Using 3, 4-Diaminobenzoic Acid Chelated Zirconium-Silane Hybrid Sol-Gels
}

\author{
P.C. Rajath Varma \\ Technological University Dublin, rajath.varma@tudublin.ie \\ John Colreavy \\ Technological University Dublin, john.colreavy@tudublin.ie \\ John Cassidy \\ Technological University Dublin, john.cassidy@tudublin.ie
}

See next page for additional authors

Follow this and additional works at: https://arrow.tudublin.ie/cenresart

Part of the Materials Chemistry Commons

\section{Recommended Citation \\ Varma, P., et al.: Corrosion Protection of AA 2024-T3 Aluminium Alloys Using 3, 4-Diaminobenzoic Acid Chelated Zirconium-Silane Hybrid Sol-Gels. Thin Solid Films, Volume 518, Issue 20, 2 August 2010, Pages 5753-5761. doi:10.1016/j.tsf.2010.05.088}

This Article is brought to you for free and open access by the Crest: Centre for Research in Engineering Surface Technology at ARROW@TU Dublin. It has been accepted for inclusion in Articles by an authorized administrator of ARROW@TU Dublin. For more information, please contact arrow.admin@tudublin.ie, aisling.coyne@tudublin.ie,gerard.connolly@tudublin.ie. Funder: Enterprise Ireland (Applied Research Enhancement)

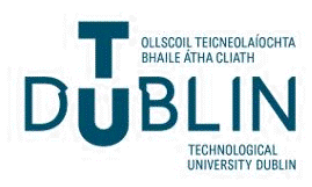




\section{Authors}

P.C. Rajath Varma, John Colreavy, John Cassidy, Mohamed Oubaha, Colette McDonagh, and Brendan Duffy

This article is available at ARROW@TU Dublin: https://arrow.tudublin.ie/cenresart/3 


\title{
Corrosion protection of AA 2024-T3 aluminium alloys using 3, 4-diaminobenzoic acid chelated zirconium-silane hybrid sol-gels
}

\author{
P.C. Rajath Varma ${ }^{\text {a }}$, John Colreavy ${ }^{\text {a }}$, John Cassidy ${ }^{\text {b }}$, Mohamed Oubaha ${ }^{\text {, }}$, \\ Colette McDonagh ${ }^{\mathrm{c}}$, Brendan Duffy ${ }^{\mathrm{a}, *}$ \\ a Centre for Research on Engineering Surface Technology (CREST), FOCAS Institute, Dublin Institute of Technology, 13 Camden Row, Dublin 8, Ireland \\ b School of Chemical and Pharmaceutical Sciences, Dublin Institute of Technology, Kevin St., Dublin 8, Ireland \\ c National Centre for Sensor Research (NCSR), Dublin City University, Dublin 9, Ireland
}

\section{A R T I C L E I N F O}

\section{Article history:}

Received 29 May 2009

Received in revised form 26 April 2010

Accepted 20 May 2010

Available online $\mathrm{xxxx}$

\section{Keywords:}

Ormosil

Zirconium

Chelate

Coating

Nanoparticles

\begin{abstract}
A B S T R A C T
Organic-inorganic polymers formed by hydrolysis/condensation reactions of alkoxide precursors, such as organically modified silanes (Ormosils) are used for several industrial applications such as electronic, optical and protective anticorrosion coatings. Such materials possess superior chemical stability, physical strength and scratch resistance characteristics when compared to organic polymers. Further performance improvement can be achieved through the incorporation of zirconium and titanium based nanoparticles, also formed through from precursors via the sol-gel process. However due to the inherent reactivity differences of the above precursors, they must be hydrolysed separately before being combined for final condensation. Zirconium precursors are commonly chelated using acetic acid or acetyl acetonate prior to hydrolysis, to lower the hydrolysis rate.

In this body of work, 3,4-diaminobenzoic acid (DABA) and acetyl acetonate (acac) were compared as chelating ligands for controlling the hydrolysis reactions of zirconium n-propoxide to form nanoparticles within a silane sol matrix. The sols were applied as coatings on aerospace grade aluminium alloy AA 2024-T3 and characterised by physical, spectroscopical, microscopical, electrochemical and calorimetric techniques. The electrochemical properties of the coatings, as characterised by EIS and PDS, correlated with neutral salt spray evaluations confirming that the use of DABA as a chelating ligand significantly improved the coating performance when compared to the traditional diketone ligand. The data indicates the anticorrosion properties of the nitrogen rich chelate have a key role in protecting the alloy through the formation of smaller zirconium nanoparticles, thus improving the polymer network stability.
\end{abstract}

(c) 2010 Elsevier B.V. All rights reserved.

\section{Introduction}

As the most abundant metal in the earth's crust ( $8.1 \%$ by mass), aluminium is used extensively in alloys for products ranging from kitchen utensils and drink cans to engineering, architectural and automotive components. However aluminium is not found free in nature, but chiefly in bauxite due to its reactivity and must be alloyed for engineering purposes, usually with copper and magnesium. Consequently products of aluminium and its alloys need to be protected from atmospheric conditions in order to maintain their appearance and performance. This is important if the alloy contains high levels of secondary phase particles, such as copper intermetallics, which may promote galvanic activity. The current state of the art for protecting aluminium alloys involves the use of hexavalent chromium technology in the form of conversion coatings and pigmented

\footnotetext{
* Corresponding author. Tel.: +353 1402 7964; fax: +35314027941. E-mail address: bduffy@dit.ie (B. Duffy).
}

anticorrosion primers [1]. However in the interest of human health $[2,3]$ and environmental concerns, alternative solutions are being pursued. For engineering applications organic polymers (polyesters, polyamides, alkyds, and polyurethane) [4], conductive polymers (polyaniline and polypyrrole) [5] and sol-gel derived organicinorganic hybrid materials have emerged as promising $\mathrm{Cr}^{6+}$ alternatives [6].

The sol-gel process can be used to form nano structured inorganic films (typically $200 \mathrm{~nm}$ to $10 \mu \mathrm{m}$ in overall thickness) that are more resistant than metals to oxidation, corrosion, erosion and wear while also possessing good thermal and electrical properties. The chemistry of the sol-gel process is well known [7-9] with excellent reviews $[6,10,11]$ and books [12] available. The most common sol-gel materials used as coatings are based on organically modified silicates (Ormosils), which are formed by the hydrolysis and condensation of trialkoxy silanes precursors $[13,14]$.

Although initial studies of Ormosils as protective coatings on aluminium found that they lacked chromium's self-healing properties $[15,16]$, the inclusion of zirconium chemistries was found to improve 
the coatings' performance considerably [17], especially alkali resistance. Some United States Air Force studies investigated various routes towards improving coating performance including the use of rare-earth metal salts [18], amine cross-linkers [19-21], supramolecular inclusion and organic corrosion inhibitors [22,23].

Similar approaches were investigated by European research groups which concentrated on epoxy functionalised silane-zirconium systems by adding cerium [24], azole based organic inhibitors in host molecules [25,26] and bis-silanes [27]. Further published data suggests that the route of zirconium inclusion is important, as the choice of chelating ligand may have an effect of the final coating performance [28]. This would be in agreement with previous studies which found that hydrolysis of zirconium alkoxides can be controlled to deliver nanoparticles of varying sizes $[29,30]$.

In the present work zirconium n-propoxide was chelated separately with two ligands, 3, 4-diaminobenzoic acid (DABA) and with acetyl acetonate (acac), hydrolysed and combined with prehydrolysed 3-(trimethoxysilyl) propylmethacrylate (MAPTMS) to obtain two hybrid sol-gels. The sols were then spin coated onto aerospace AA 2024-T3 aluminium alloy panels to compare their structural properties and anticorrosion performance. The structural properties of the sol were characterised by ${ }^{29} \mathrm{Si}$ nuclear magnetic resonance (NMR) and Fourier transform infra red (FTIR) spectroscopy. The sol-gel network stability was determined by differential scanning calorimetry (DSC), while the surface morphology of the coatings was studied by atomic force microscopy (AFM). The corrosion properties were compared using electrochemical impedance spectroscopy (EIS), potentiodynamic scanning (PDS) and neutral salt spray (NSS) techniques. The DABA modified coating displays superior performance to the acac equivalent, which we propose is due to both improvements in polymeric network stability and the corrosion inhibition properties of the DABA species. This dual functionality of DABA within the hybrid coatings is significant, especially in harsh environments where aluminium alloys are dependent on protective coatings for long term usage.

\section{Experimental details}

\subsection{Sol-gel synthesis}

The sol-gel precursors used were 3-(trimethoxysilyl)propylmethacrylate (MAPTMS, Assay 99\%) and zirconium (IV) n-propoxide (TPOZ, Assay $~ 70 \%$ in propanol). The ligands used were 3,4dimaniobenzoic acid (DABA, $\mathrm{C}_{4} \mathrm{H}_{6} \mathrm{O}_{2}$, Assay $>98 \%$ ), acetylacetone (acac, $\mathrm{CH}_{3} \mathrm{COCH}_{2} \mathrm{COCH}_{3}$, Assay 99\%). All materials were purchased from Sigma Aldrich ( $\mathrm{Irl}$ ) and used as received, without further purification. The structures of two ligands used in this work are shown in Fig. 1.

(a)

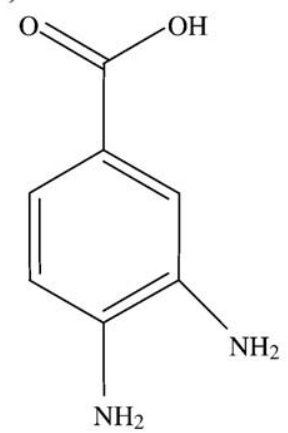

(b)<smiles>CC(=O)CC(C)=O</smiles>

The ligand functionalized hybrid sols were prepared according to the experimental schematic in Fig. 2. The silane precursor, MAPTMS was pre-hydrolysed using $0.01 \mathrm{~N} \mathrm{HNO}_{3}$ for $45 \mathrm{~min}$ (solution A). Simultaneously, TPOZ was chelated using one of two ligands (Fig. 1), at a 1:1 molar ratio for $45 \mathrm{~min}$ (solution $\mathrm{B}$ ) to form a zirconium complex. For the $\mathrm{Zr} / \mathrm{DABA}$ complex, $5 \mathrm{ml}$ of ethanol was added to enhance the dissolution of DABA. Solution A was slowly added to solution B over $10 \mathrm{~min}$ and was characterised by an exothermic reaction indicating the hydrolysis of the remaining propoxy bonds on the zirconium precursor, rather than a physical dispersion, was occurring. Following a further $45 \mathrm{~min}$, water ( $\mathrm{pH} 7$ ) was added to the mixture to give a final molar ratio of 2.5:1:1:5 (MAPTMS: Ligand: TPOZ: $\mathrm{H}_{2} \mathrm{O}$ ), as used previously [31,32]. For comparative purposes a MAPTMS sol-gel was prepared by combining the silane precursor, dilute $\mathrm{HNO}_{3}$ (aq) as catalyst, ethanol as solvent and water for hydrolysis with a molar ratio of $1 / 0.001 / 2.5 / 5$ (MAPTMS/ $/ \mathrm{HNO}_{3} / \mathrm{ETOH} /$ $\mathrm{H}_{2} \mathrm{O}$ ). All reaction mixtures were stirred for 15-16 h prior to coating on AA2024-T3 panels and curing. For description purposes the final sol-gel coating materials will be referred in shorthand notation as MAPTMS/Zr/Ligand (eg. MAPTMS/Zr/DABA).

\subsection{Coating preparation}

AA2024-T3 aluminium panels $(150 \mathrm{~mm} \times 100 \mathrm{~mm})$ were sourced from Amari Irl, Dublin. The panels were degreased with isopropanol, alkaline cleaned using Oakite $61 \mathrm{~B}{ }^{\circledR}$ (Chemetall, UK) by immersion at $60{ }^{\circ} \mathrm{C}$ for $1 \mathrm{~min}$ and washed in warm deionised water. The sols were filtered using a $0.45 \mu \mathrm{m}$ syringe filter (Whatman, UK) and spin coated on AA 2024-T3 alloy at up to $1000 \mathrm{rpm}$ and cured for $12 \mathrm{~h}$ at $100{ }^{\circ} \mathrm{C}$. The final thickness of all sol-gel coating was $3 \mu \mathrm{m}( \pm 0.5 \mu \mathrm{m})$, as measured using an Elcometer ${ }^{\circledR}$ non destructive coating thickness gauge. All finishes were touch dry within $15-16 \mathrm{~h}$, with a gloss finish.

\subsection{Measurements}

Electrochemical data was obtained using a Solartron SI 1287/ 1255B system comprising of a frequency analyser and potentiostat. Electrochemical impedance data was measured using the electrochemical cells prepared by slicing polypropylene sample bottles (25 mm diameter) $10 \mathrm{~mm}$ from the base which were then secured on the sol-gel coated aluminium substrate using a $2 \mathrm{~K}$ epoxy adhesive (Araldite, Radionics (Irl.)). A dilute Harrison's solution was used as electrolyte $\left(0.35 \mathrm{wt} . \%\left(\mathrm{NH}_{4}\right)_{2} \mathrm{SO}_{4}\right.$ and $\left.0.05 \mathrm{wt} . \% \mathrm{NaCl}\right)$ as it contains sulphate and chloride ions in order to mimic high altitude atmospheric pollutants. All measurements were made at the open circuit potential (OCP, $E_{\text {oc }}$ ) with an applied $10 \mathrm{mV}$ sinusoidal perturbation in the frequency range $10^{6}$ to $10^{-2} \mathrm{~Hz}$ (10 points per decade). The coated metal acted as the working electrode, a silver/silver chloride

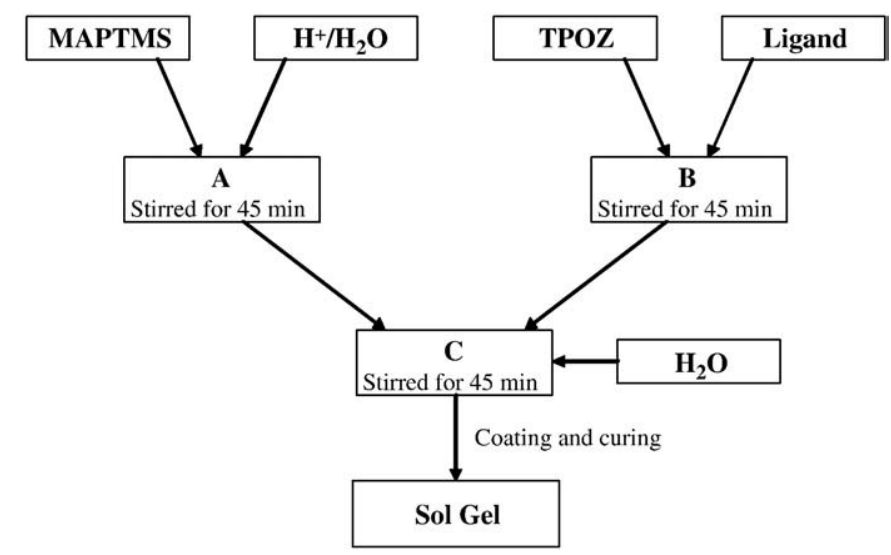

Fig. 1. The ligands used to modify zirconium (a) 3,4,-diaminobenzoic acid, (b) acetylacetone.

Fig. 2. Flow chart for the preparation of hybrid sols. 
$(\mathrm{Ag} / \mathrm{AgCl})$ electrode was used as the reference electrode and platinum mesh as the counter electrode.

PDS was performed using an electrochemical cell (PAR K0235 Flat Cell) with an exposed area of $0.78 \mathrm{~cm}^{2}$ in an aerated Harrison's solution $\left(3.5 \%(\mathrm{w} / \mathrm{v})\left(\mathrm{NH}_{4}\right)_{2} \mathrm{SO}_{4}\right.$ and $\left.0.5 \%(\mathrm{w} / \mathrm{v}) \mathrm{NaCl}\right)$. All scans were acquired in the region from $-0.8 \mathrm{~V}$ to $+0.8 \mathrm{~V}$ versus the open circuit potential, at a scan rate of $1 \mathrm{mV} / \mathrm{sec}$ at room temperatures $20( \pm 2)^{\circ} \mathrm{C}$.

${ }^{29} \mathrm{Si}$ NMR spectroscopy was used to identify the degree of hydrolysis and condensation of the organosilane skeleton structure in each system, as measured by the number of hydroxo and oxo bridges, respectively. These experiments were performed at room temperature on liquid samples employing a Bruker $400 \mathrm{MHz}$ spectrometer. Classical $T$ notation is used for the different silicate species depending on the number of oxygen bridging atoms, $i$ subscripts and $j$ superscripts represent the number of hydroxo bridges and the number of oxo functions respectively. The accumulation was carried out at a frequency of $79.49 \mathrm{MHz}$, with a pulse duration of $8 \mathrm{~ms}$ and a spectral width of 32,051 ppm for 30,000 scans. The chemical shifts were referenced against tetramethylsilane (TMS) as an external reference. Line broadening of $10 \mathrm{~Hz}$ was used for free induction decay processing. Each recorded spectrum is an average of all spectra obtained during the instrument acquisition time.

Samples for DSC were prepared by dropping $10 \mu$ of the liquid sol into aluminium sample pans and curing at $100{ }^{\circ} \mathrm{C}$ for $1 \mathrm{~h}$ in an oven. All calorimetric measurements were carried out between $50{ }^{\circ} \mathrm{C}$ and $300{ }^{\circ} \mathrm{C}$ in open pans using a Rheometric Scientific DSC QC instrument under an air atmosphere at a heating rate of $10^{\circ} \mathrm{C}$ per minute.

AFM studies were performed using an Asylum MFP-3D microscope, fitted with an aluminium coated silicon tip at a scan rate of $0.7 \mathrm{~Hz}$. Damage to the tip and sample surface was minimised by running the experiment in tapping mode.

The chemical bonding within the zirconium complexes was characterised by FTIR spectroscopy using a Perkin Elmer GX instrument operating in the transmission mode. The condensed sol-gels were dried at $100{ }^{\circ} \mathrm{C}$ for $12 \mathrm{~h}$. The dried powders were then crushed with $\mathrm{KBr}$ pellets to form disks and analysed in transmission mode.

The corrosion resistance of the coated AA2024-T3 alloys was evaluated by exposure of the scribed samples to salt fog atmosphere generated from an aqueous $5 \mathrm{wt} . \% \mathrm{NaCl}$ solution at $35( \pm 1)^{\circ} \mathrm{C}$ for $168 \mathrm{~h}$ according to ASTM B117 specifications [33]. The non coated side and edges of the panels were protected using water a based polyurethane coating (Alberdink $®$ ). The edges were further protected with $3 \mathrm{M}$ insulation tapes.

\section{Results and discussion}

\section{1. ${ }^{29}$ Si NMR spectroscopy}

The ${ }^{29} \mathrm{Si}$ NMR spectrum of the pure MAPTMS precursor shows a single $T_{0}^{0}$ peak located at $-42.9 \mathrm{ppm}$ (Fig. 3) confirming the absence of any hydrolysed or modified species. The hydrolysis-condensation reaction of the MAPTMS was followed for $16 \mathrm{~h}$ with spectra recorded

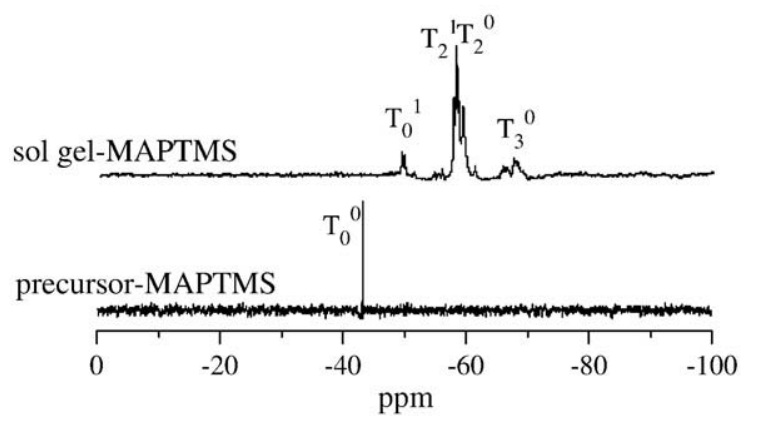

Fig. 3. ${ }^{29}$ Si NMR of MAPTMS precursor and MAPTMS sol-gel. within this duration (Fig. 3). The final spectrum shows the disappearance of the initial $T_{0}^{0}$ group observed in the precursor coupled with the appearance of 3 bands located around $-50,-59,-69 \mathrm{ppm}$ in the typical $T_{1}, T_{2}$ and $T_{3}$ regions respectively [32]. These bands are actually composed of several peaks indicating different degrees of hydrolysis for the silicon atom in each configuration, as summarised in Table 1. At this stage, the results demonstrate that the molecular system is composed of a mixture of oligomers of $T_{1}, T_{2}$ and $T_{3}$.

Fig. 4 shows the ${ }^{29} \mathrm{Si}$ NMR spectra of the MAPTMS/Zr/acac at different hydrolysis stages. The pre-hydrolysis of MAPTMS (Solution A), results in appearance of $T_{1}^{2}(-49.5)$ and $T_{2}^{0}(-59.6)$ species and a small amount of $T_{0}^{0}$, indicative of the precursor. The disappearance of the $T_{1}^{2}$ species was observed when Solution B was introduced and can be related to self-condensation reactions catalysed by Solution B. This mixture also involves the formation of new species such as $T_{1}^{1}$ (-50.8), $T_{2}^{1}(-58.7)$ and a broad spectrum of $T_{3}^{0}(-68.6)$. The formation of the sol-gel (final step) is accompanied by an increase in siloxane bond signal, which was observed by an increase in $T_{3}^{0}$ species concentration at $-68.9 \mathrm{ppm}$ and disappearance of $T_{2}^{1}$ and $T_{1}^{1}$ species.

The ${ }^{29} \mathrm{Si}$ NMR spectrum of the corresponding MAPTMS/Zr/DABA material involves various steps as shown in Fig. 5. The spectrum final sol-gel possessed similar peaks to that of MAPTMS/Zr/acac, although it should be noted that $T_{2}^{1}$ species was not formed in the second step (Fig. 5). The $T_{2}^{0}$ and $T_{3}^{0}$ signals were also found to be more intense, which proves that the level of condensed siloxane bonds is higher for MAPTMS/Zr/DABA than MAPTMS/Zr/acac.

\subsection{Particle size analysis}

Two particles size ranges were formed for zirconium rich sol-gels while only one was formed for the MAPTMS sol-gel. Particle size measurements of the sol-gels (Fig. 6) indicate that the level of influence the ligands have on the formation of the zirconium nanoparticles as the lowest particle sizes are found for MAPTMS/Zr/ DABA followed by MAPTMS/Zr/acac. Indeed, it seems that the DABA tends to form complexes with only one zirconium atom, whereas acac has the ability to form oligomers with different degrees of condensation depending on the keto-enol form (Scheme 1).

\subsection{AFM analysis}

AFM was used for the characterization of the surface topography of the treated substrates. The AFM image of the MAPTMS coating (Fig. 7 (a)) shows a porous topography with no particles detectable at the surface. For the other samples, some nanoparticles are detected in the coating surface as seen previously [34,35]. The largest particles observed on MAPTMS/Zr/acac (Fig. 7 (b)) are likely to result from agglomeration of smaller particles in a heterogeneous manner in the sol-gel matrix. In contrast, the AFM images obtained for MAPTMS/Zr/ DABA coating (Fig. 7 (c)) revealed a smoother surface and uniformly distributed smaller particles.

Table 1

Assignments of ${ }^{29} \mathrm{Si}$ NMR signals for monomeric and oligomeric species obtained from the MAPTMS hydrolysis-condensation [31].

\begin{tabular}{lll}
\hline Species & Notation & Chemical shift $(\mathrm{ppm}, \pm 0.1)$ \\
\hline $\mathrm{R}-\mathrm{Si}-(\mathrm{OMe})_{3}$ & $T_{0}^{0}$ & -42.3 \\
$\mathrm{R}-\mathrm{Si}-(\mathrm{OMe})_{2} \mathrm{OH}$ & $T_{0}^{1}$ & -41.3 \\
$\mathrm{R}-\mathrm{Si}-(\mathrm{OMe}) \mathrm{OH}_{2}$ & $T_{0}^{2}$ & -40.6 \\
$\mathrm{R}-\mathrm{Si}-(\mathrm{OH})_{3}$ & $T_{0}^{3}$ & -40.1 \\
$\mathrm{R}-\mathrm{Si}-(\mathrm{OMe})_{2}-\mathrm{OSi}$ & $T_{1}^{0}$ & -49.9 \\
$\mathrm{R}-\mathrm{Si}-(\mathrm{OMe}) \mathrm{OH}-\mathrm{OSi}$ & $T_{1}^{1}$ & -50.5 \\
$\mathrm{R}-\mathrm{Si}-(\mathrm{OH})_{2}-\mathrm{OSi}$ & $T_{1}^{2}$ & -49.3 \\
$\mathrm{R}-\mathrm{Si}-(\mathrm{OMe})-(\mathrm{OSi})_{2}$ & $T_{2}^{0}$ & -59.1 \\
$\mathrm{R}-\mathrm{Si}-(\mathrm{OH})-(\mathrm{OSi})_{2}$ & $T_{2}^{1}$ & -58.5 \\
$\mathrm{R}-\mathrm{Si}(\mathrm{OSi})_{3}$ & $T_{3}^{0}$ & -67.4 \\
\hline
\end{tabular}




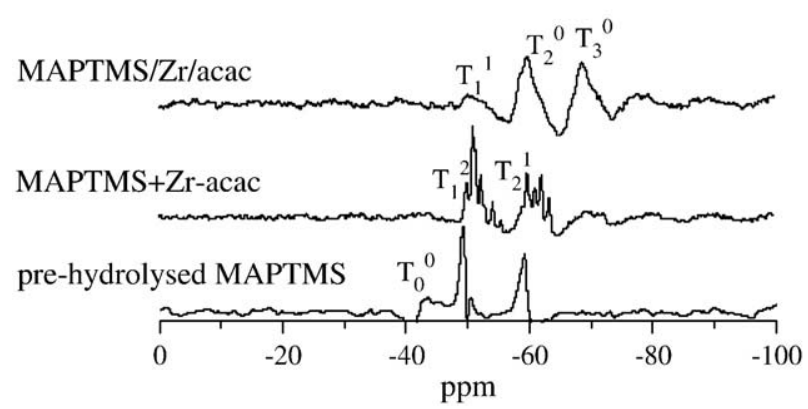

Fig. 4. ${ }^{29} \mathrm{Si}$ NMR of pre-hydrolysed MAPTMS, pre-hydrolysed MAPTMS + Zr-acac and MAPTMS/Zr/acac.

\subsection{FTIR analysis}

FTIR spectroscopy is a powerful characterisation technique that can be used to identify the coordination of carboxylic acid and $\beta$-diketone ligands with metal alkoxides [29]. To distinguish between the coordination of the ligands to the zirconium precursor, 2 complexes were synthesised and their respective infrared spectra recorded in the $1300-1800 \mathrm{~cm}^{-1}$ range, as represented in Fig. 8. This range is well known to be where carboxylic vibration bands are active [36].

The $\mathrm{Zr}$-DABA complex possesses two peaks around 1635 and $1533 \mathrm{~cm}^{-1}$, which are ascribable to the symmetric $\left(\nu_{\mathrm{s}}\right)$ and asymmetric stretching $\left(\nu_{\mathrm{as}}\right)$ vibrations of the carboxylic group $\left(\mathrm{COO}^{-}\right)$ respectively [38]. With a $\Delta v\left(\mathrm{COO}^{-}\right)$value of $102 \mathrm{~cm}^{-1}$, the chelate can be said to be bidentate.

For the $\mathrm{Zr}$-acac complex, a strong band was seen at $1730 \mathrm{~cm}^{-1}$ which can be ascribed to the ketone carbonyl vibration [37]. Two other bands are observed at 1598 and $1523 \mathrm{~cm}^{-1}$ and are attributed to the formation of the carbonyl and vinyl bonds within the prevalent keto-enol form of the ketone (Scheme 1).

In this configuration the unsaturated vinylic group acts as an auxochromic group, thus provoking a bathochromic shift of the carbonyl group via a mesomeric effect. It is possible that the complex synthesised with acac can exist in two different configurations, due to the presence of the methylene bridge in the aliphatic chain between the ketone and the alcohol functions, which can confer a higher flexibility to the molecule, thereby facilitating binding with two zirconium atoms.

\subsection{Thermal stability}

DSC analysis was performed on partially cured sol-gel materials between $50{ }^{\circ} \mathrm{C}$ and $300{ }^{\circ} \mathrm{C}$, although the working temperature for a typical coating would be likely to be well below $250^{\circ} \mathrm{C}$. From the thermal stability study it can be seen that the MAPTMS sol-gel had not fully cured at $100{ }^{\circ} \mathrm{C}$ as the exothermic signal at $130{ }^{\circ} \mathrm{C}$ suggests. In comparison it is clear that the influence of zirconium has facilitated

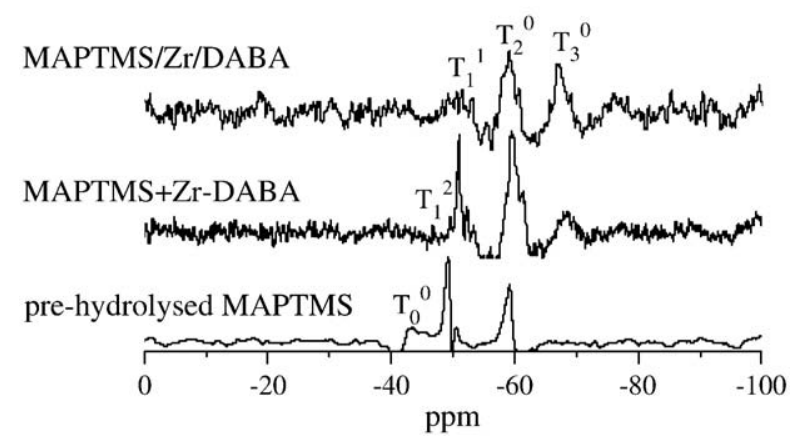

Fig. 5. ${ }^{29} \mathrm{Si}$ NMR of pre-hydrolysed MAPTMS, pre-hydrolysed MAPTMS + Zr-DABA and MAPTMS/Zr//DABA.

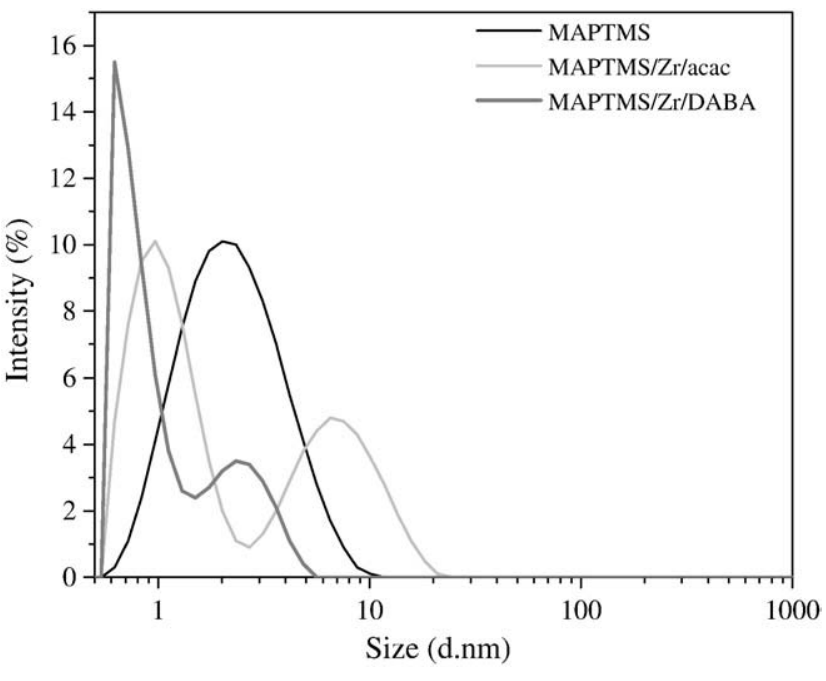

Fig. 6. Particle size distribution of MAPTMS and ligand modified sol-gels.

curing at $100^{\circ} \mathrm{C}$ and can be claimed that the ligand choice has a profound effect on the glass transition temperature $\left(T_{\mathrm{g}}\right)$ of each material (Fig. 9). Two distinct transitions can be attributed to the zirconium nanoparticles and the silane network. The MAPTMS/Zr/ DABA displays higher $T_{\mathrm{g}}$ values when compared to MAPTMS/Zr/acac. This highlights the difference (by up to $35^{\circ} \mathrm{C}$ ) in the chelating ability of the ligand and potential advantages of improving the sol-gel network stability. Thermal stability can be arranged in increased order of the stability of polymer:

MAPTMS $<$ MAPTMS / Zr / acac $<$ MAPTMS / Zr / DABA

\subsection{Electrochemical evaluation}

The electrochemical properties of the sol-gel coatings give vital early information on their potential long term performance in aggressive challenging environments. AC techniques are used to estimate electrochemical interactions at the coating metal interface at the open circuit potential, while DC techniques provide information on the corrosions rate, pitting susceptibility, passivity and cathodic behaviour of electrochemical cells.

\subsubsection{EIS}

EIS involves applying an AC voltage at the open circuit potential (OCP), with a sinusoidal amplitude of varying frequency across a coating in contact with an aggressive electrolyte. The coatings' resistance to the AC signal, or impedance, varies according to the applied frequency and is graphically represented on a Bode frequency plot. The phase angle associated with the impedance gives valuable information on the film properties such as barrier performance and interfacial activity. This activity is often seen as a build up of oxide material, usually corrosion product which may prevent charge transfer at the metal surface thus increasing the effective interfacial capacitance. The process can be modelled as an equivalent electrical circuit as explained elsewhere [39].

The impedance data for the coatings is shown after exposure to Harrison's solution electrolyte after $1 \mathrm{~h}$ (Fig. 10) and $72 \mathrm{~h}$ (Fig. 11).
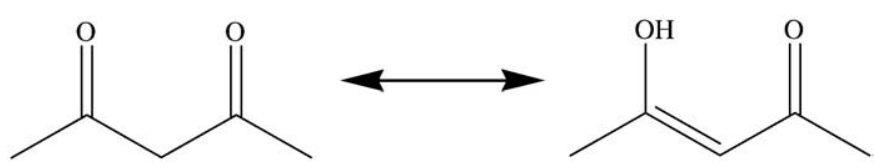

Scheme 1. Keto-enolic equilibrium of the acetylacetone molecule. 

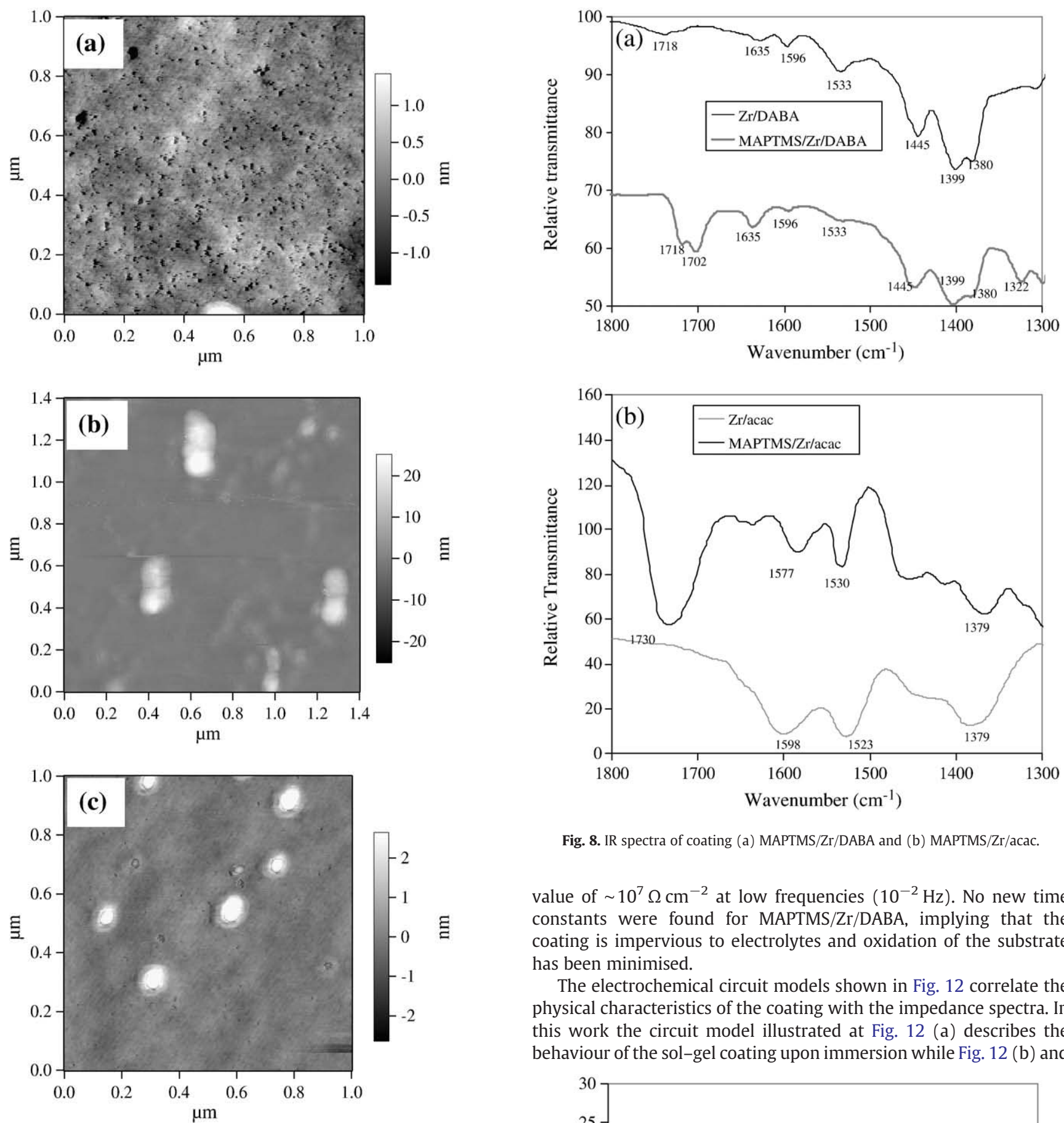

Fig. 8. IR spectra of coating (a) MAPTMS/Zr/DABA and (b) MAPTMS/Zr/acac.

value of $\sim 10^{7} \Omega \mathrm{cm}^{-2}$ at low frequencies $\left(10^{-2} \mathrm{~Hz}\right)$. No new time constants were found for MAPTMS/Zr/DABA, implying that the coating is impervious to electrolytes and oxidation of the substrate has been minimised.

The electrochemical circuit models shown in Fig. 12 correlate the physical characteristics of the coating with the impedance spectra. In this work the circuit model illustrated at Fig. 12 (a) describes the behaviour of the sol-gel coating upon immersion while Fig. 12 (b) and

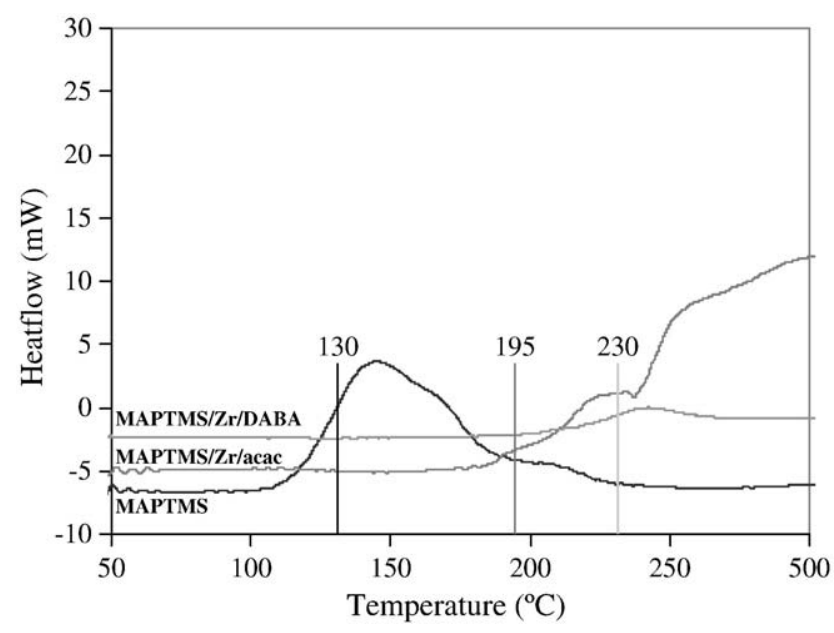

Fig. 7. Atomic force microscopy (AFM) images of sol-gel films (a) MAPTMS (b) MAPTMS/Zr/acac and (c) MAPTMS/Zr/DABA.

The Bode plot for MAPTMS coating possesses two time constants in the initial hour of exposure. The high frequency time constant results from the capacitance of the sol-gel layer, while the second time constant observed in the $10^{-1} \mathrm{~Hz}$ frequency range can be ascribed to the initial early penetration of water and chloride ions through the porous film. A drop in the high frequency phase angle from 1 to $72 \mathrm{~h}$ was observed for the MAPTMS coating, implying the coating is incapable of preventing water and electrolyte ingress.

The zirconium rich coatings possessed one time constant during the initial hour of exposure, indicating that the coating is intact and no corrosion process initiated. The MAPTMS/Zr/DABA coating was better at maintaining its electrochemical properties with a high impedance

Fig. 9. DSC studies of various sol-gel. 

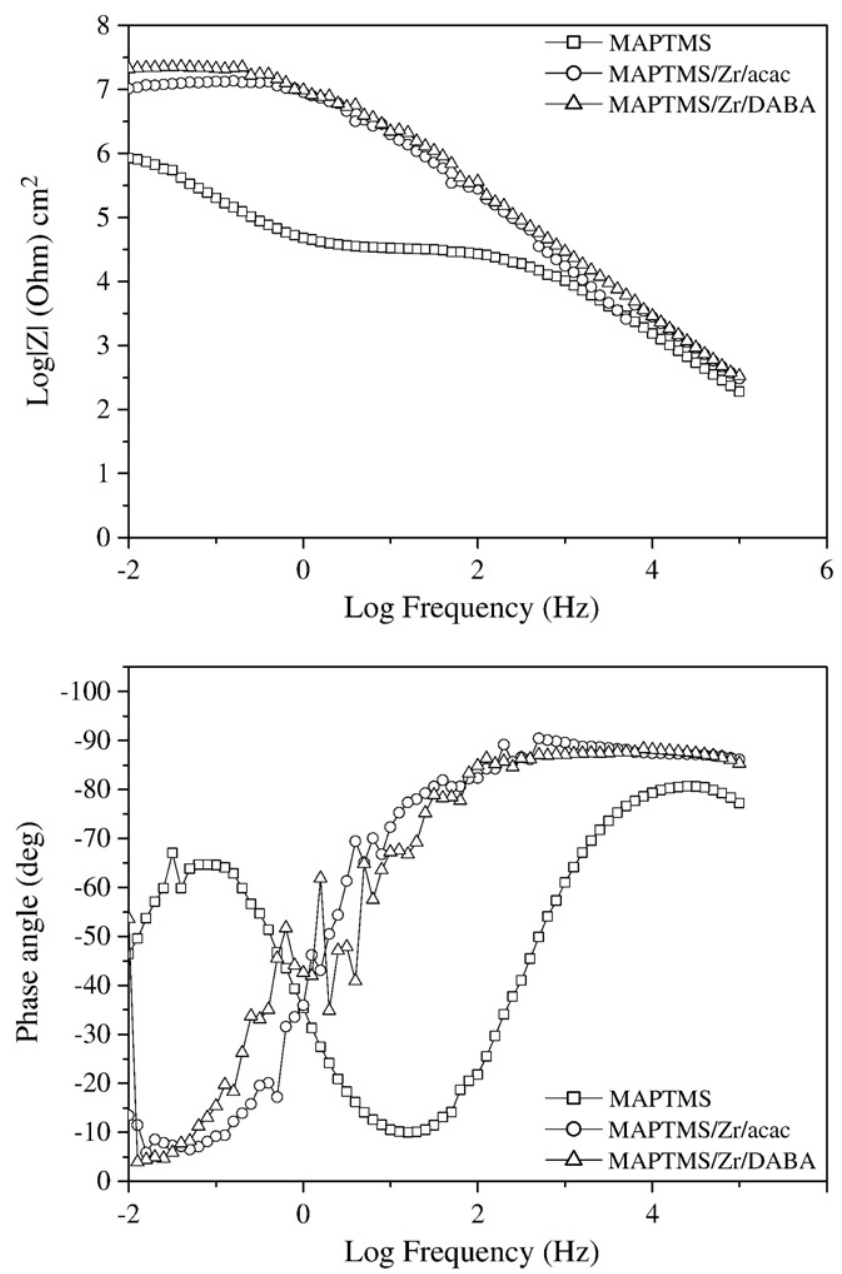

Fig. 10. Bode plots of coatings after $1 \mathrm{~h}$ immersion in dilute Harrison's solution.

(c) describes the same system at $24 \mathrm{~h}$ and $72 \mathrm{~h}$ of immersion. Constant phase elements (CPE) were used instead of capacitances in all fittings presented in the work as the phase angle observed never reached $-90^{\circ}$. The parameter $R_{\text {sol }}$ corresponds to the solution resistance, $R_{\text {coat }}$ is the coating resistance, $C_{\text {coat }}$ is the coating capacitance, $R_{\mathrm{int}}$ is the metal/coating resistance, and $C_{\mathrm{dl}}$ accounts for the double layer capacitance. The Warburg element is represented as $W$ and accounts for the diffusion of oxygen and water into the coating [39]. It should be noted that as the solution was unstirred, and considering that the metallic surface is covered by a coating, the rate determining step of the electrode process is probably not the activation of that charge transfer and thus, the physical values for Warburg impedance in Table 2 can only be used to differentiate the samples qualitatively, but not quantitatively. The fitting parameters are illustrated in Table 2. For the purposes of managing the iterations, the error on the fit was restricted to $\pm 2 \%$ for all calculated variables.

The coating capacitance $\left(C_{\text {coat }}\right)$ evolution is related to the penetration of water through the coating and is expected to increase with exposure time and coating degradation [40]. Fig. 13 (a) displays the evolution of $C_{\text {coat }}$ over time when immersed in dilute Harrison's solution. The coating capacitance of MAPTMS exhibits significantly faster growth due to the ingress of water through the coatings porous topography of MAPTMS (Fig. 7 (a)). During the initial immersion hours, MAPTMS/Zr/acac and MAPTMS/Zr/DABA show similar capacitance values with the lowest capacitance observed for the latter. The measured capacitance values for MAPTMS/Zr/DABA were about one and three orders of magnitude lesser than MAPTMS/Zr/acac and MAPTMS respectively.
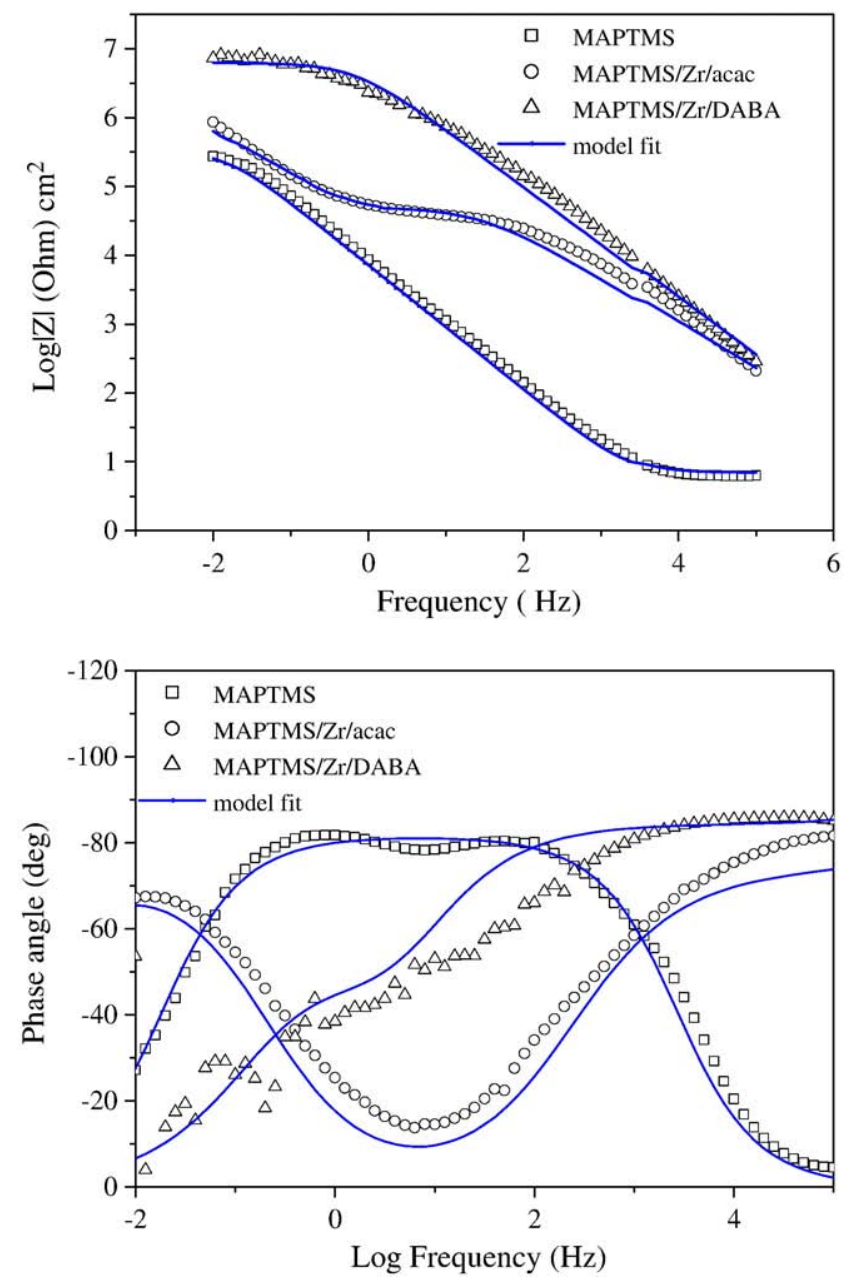

Fig. 11. Bode plots with respective fittings for various sol-gel coatings after $72 \mathrm{~h}$ of dilute Harrison's solution.

The low frequency impedance measurements are dependent on the sol-gel coating/alloy interface resistance $\left(R_{\text {int }}\right)$ which tend to decrease over time (Fig. 13 (b)). Characteristically, the drop in $R_{\text {int }}$ is

(a)

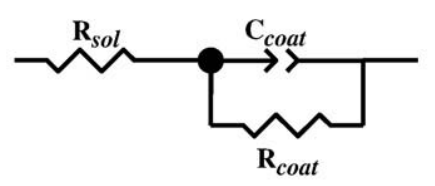

(b)

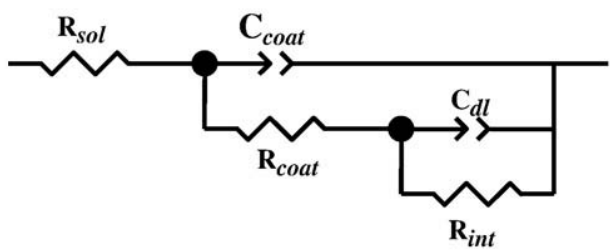

(c)

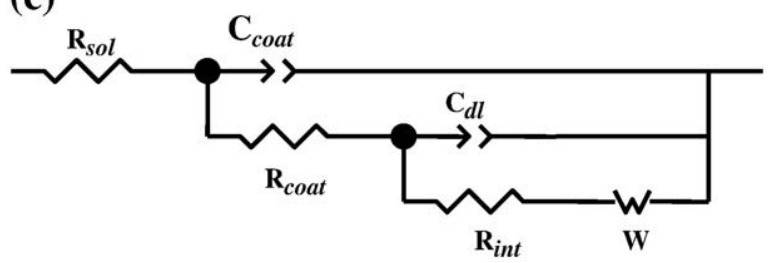

Fig. 12. Equivalent circuit used to fit experimental data: (a) initial immersion time, (b) and (c) 24 to $72 \mathrm{~h}$ of immersion. 
Table 2

Parameters of various sol-gel film, obtained from fitting of the experimental impedance spectra with different equivalent circuits.

\begin{tabular}{lllllll}
\hline Sol-gel coating & MAPTMS & \multicolumn{3}{l}{$\mathrm{Si} / \mathrm{Zr} / \mathrm{DABA}$} & \multicolumn{2}{l}{$\mathrm{Si} / \mathrm{Zr} / \mathrm{acac}$} \\
\hline Immersion time (hour) & 0 & 72 & 0 & 72 & 0 & 72 \\
Equivalent circuit & $12 \mathrm{C}$ & $12 \mathrm{C}$ & $12 \mathrm{~A}$ & $12 \mathrm{~B}$ & $12 \mathrm{~A}$ & $12 \mathrm{~B}$ \\
$C_{\text {coat }}-T\left(\times 10^{-5} \mathrm{~S} \mathrm{~cm}^{-2}\right)$ & 0.0051 & 2.110 & 0.0011 & 0.0035 & 0.0012 & 0.011 \\
$C_{\text {coat }}-P$ & 0.8604 & 0.9058 & 0.9225 & 0.8604 & 0.9291 & 0.8018 \\
$R_{\text {coat }}\left(\times 10^{6} \Omega \mathrm{cm}^{2}\right)$ & 0.039 & 0.033 & 20.1 & 6.29 & 12.3 & 0.043 \\
$C_{\mathrm{dlt}}-T\left(\times 10^{-5} \mathrm{~S} \mathrm{~cm}^{-2}\right)$ & 1.32 & 1.331 & - & 0.0049 & - & 1.21 \\
$C_{\mathrm{dlt}}-P$ & $0.8096-$ & 0.8096 & - & 0.984 & - & 0.8989 \\
$R_{\mathrm{ct}}\left(\times 10^{5} \Omega \mathrm{cm}^{2}\right)$ & 8.48 & 2.74 & - & 46.9 & - & 9.96 \\
$\mathrm{~W}-\mathrm{T}\left(\times 10^{3} \mathrm{~S} \mathrm{~cm}^{-2}\right)$ & 1.20 & 199.05 & - & - & - & - \\
$W-R$ & 18 & 9.78 & - & - & - & - \\
$W-P$ & 0.41 & 0.00121 & - & - & - & - \\
\hline
\end{tabular}

significantly higher for MAPTMS when compared with zirconium coatings. This decrease occurs due to a weakening of the coating adherence following water uptake through the coating pores reaching the metal/coating interface. The water can encourage (a) coating delamination and (b) formation of oxide material or (c) formation of ligand-copper complexes at copper rich sites on the alloy. Material formation as in (b) and (c) above may act as barrier to prevent further corrosion. MAPTMS/Zr/DABA was found to have the highest interfacial resistance, with $R_{\text {int }}$ one order of magnitude higher than MAPTMS/ $\mathrm{Zr}$ /acac, possibly due to the formation of much smaller zirconium nanoparticles as confirmed from AFM studies (Fig. 6 (c)), thereby improving the network stability. The nanoparticles formed in the case of MAPTMS/Zr/acac are much larger (Fig. 13 (b)) which may have
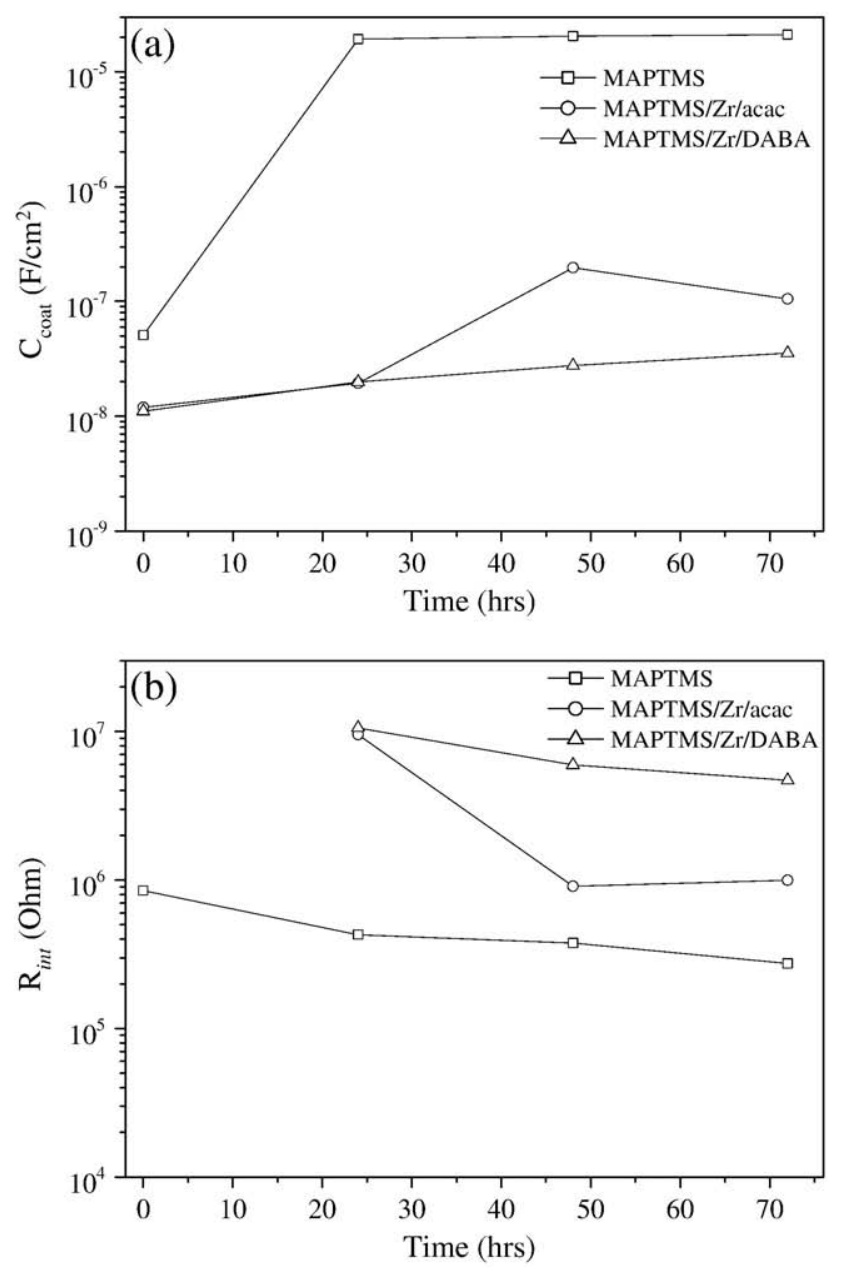

Fig. 13. (a) Evolution of $C_{\text {coat }}$ with time (b) change in $R_{\text {int }}$ with time. increased the porosity of the coating. Previous studies have shown the presence of such larger particles may disrupt the organic-inorganic network of the sol-gel polymer [41,42].

\subsubsection{PDS}

PDS gives useful information on the properties of thin coatings (less $5 \mu \mathrm{m}$ ) where properties such as corrosion current density $\left(I_{\text {corr }}\right)$ and potential $\left(E_{\text {corr }}\right)$ can be estimated by the Tafel method (Eq. (1)), and polarisation resistance $\left(R_{\mathrm{pol}}\right)$ can be calculated using Stern-Geary equation (Eq. (2)) [43]. It should be noted that the solutions were not stirred and therefore the readings are of qualitative value only.

$I_{\text {corr }}=\frac{B}{R_{\text {pol }}}$

The proportionality constant, $B$, for a particular system can be calculated from $\beta_{\mathrm{a}}$ and $\beta_{\mathrm{c}}$, the slopes of the anodic and cathodic Tafel lines as shown by [44]:

$B=\frac{\beta_{\mathrm{a}} \cdot \beta_{\mathrm{c}}}{2.303\left(\beta_{\mathrm{a}}+\beta_{\mathrm{c}}\right)}$

Potentiodynamic scans for the zirconium rich coatings are shown in Fig. 14 and the Tafel parameters all coatings are listed in Table 3. It's well known that the inclusion of zirconium improves the anticorrosion properties of ormosil coatings due to its ability to consume hydroxide ions at elevated $\mathrm{pH}$, thereby protecting the silane matrix [17]. The zirconium rich coatings reduced the corrosion current density $\left(I_{\text {corr }}\right)$ by three orders in magnitude when compared with MAPTMS alone. Further beneficial effects of the nanoparticles were observed by comparing the coatings $E_{\text {corr }}$ and polarisation resistances $\left(R_{\mathrm{pol}}\right)$. The effect of DABA as a ligand is clearly evident as the respective coating achieved the highest $E_{\mathrm{corr}}(-0.395 \mathrm{~V})$ and $R_{\mathrm{pol}}$ $\left(6.04 \times 10^{7} \Omega \mathrm{cm}^{2}\right)$ readings. The hierarchy of performance is in broad agreement with the thermal stability data and confirms that importance of the DABA as a ligand on the nano particle formation within the silane matrix and its potential to form complexes with copper rich phases at the alloy surface.

\subsection{Neutral salt spray}

The results from NSS exposure for sol-gels and bare panels are shown in Fig. 15. The coated panels were scribed prior to exposure to

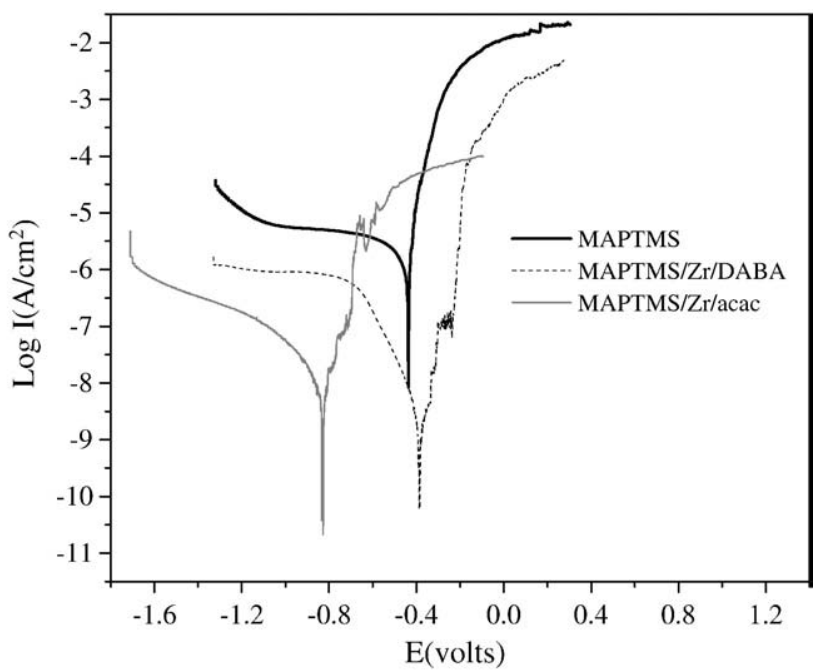

Fig. 14. Potentiodynamic plots for sol-gel coatings. 
Table 3

Corrosion parameters estimated from potentiodynamic plots of sol-gel coatings.

\begin{tabular}{|c|c|c|c|c|c|}
\hline \multirow[t]{2}{*}{ Sol-gel coatings } & $I_{\text {corr }}$ & $E_{\text {corr }}$ & $\left|\beta_{\mathrm{a}}\right|$ & $\left|\beta_{c}\right|$ & $R_{\mathrm{pol}}$ \\
\hline & $\left(\mathrm{A} / \mathrm{cm}^{2}\right)$ & $(\mathrm{V})$ & (V/decade) & (V/decade) & $\left(\Omega \mathrm{cm}^{2}\right)$ \\
\hline MAPTMS & $3.43 \times 10^{-7}$ & -0.450 & 0.023 & 0.005 & $8.51 \times 10^{3}$ \\
\hline MAPTMS/Zr/DABA & $5.11 \times 10^{-10}$ & -0.395 & 0.043 & 0.030 & $6.04 \times 10^{7}$ \\
\hline MAPTMS/Zr/acac & $2.59 \times 10^{-10}$ & -0.828 & 0.022 & 0.060 & $5.84 \times 10^{6}$ \\
\hline
\end{tabular}

the salt spray cabinet to accelerate the corrosion process. Bare AA2024-T3 was also exposed to serve as a control.

The bare aluminium was seen to corrode quite rapidly in the first $2 \mathrm{~h}$ in the absence of any protection. The panels coated with MAPTMS failed after $48 \mathrm{~h}$ with coating several pits observed (Fig. 15). The zirconium rich coatings performed better and all panels were exposed for 1 week. Pitting was observed to a greater extent on the MAPTMS/Zr/acac coating, indicating that the copper intermetallics at the alloy surface were not being passivated. The MAPTMS/Zr/DABA coating performed best, corroding only along the scribe with little pitting observed. The same order of performance as seen with DSC and EIS was observed, namely:

MAPTMS $<$ MAPTMS / Zr / acac $<$ MAPTMS / Zr / DABA

\section{Conclusion}

3,4-diaminobenzoic acid (DABA) was used as a chelating ligand to form zirconium nanoparticles within an ormosil coating on AA2024-T3 aluminium providing anticorrosion performance under aggressive conditions. The performance of the coating was compared with MAPTMS/Zr/acac and MAPTMS coatings. The electro-
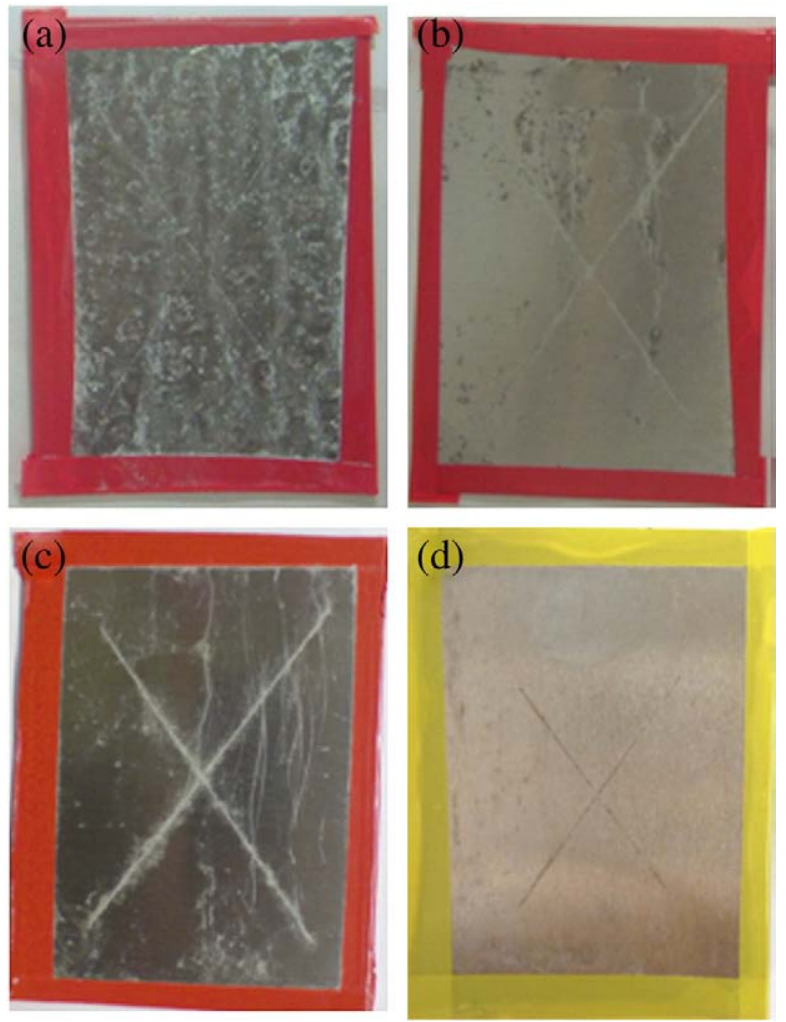

Fig. 15. Salt spray results images for (a) bare AA2024 (24 h) (b) MAPTMS (48 h) (c) MAPTMS/Zr/acac (168 h) (d) MAPTMS/Zr/DABA (168 h). chemical results indicate that while zirconium nanoparticles significantly improve the performance of the ormosil coatings, the choice of ligand is also important. Coatings formed using DABA offered the best protection with a high impedance $\left(|Z|_{0.01 \mathrm{~Hz}} \sim 10^{7} \Omega\right)$ and corrosion potential $\left(E_{\mathrm{corr}}=0.395 \mathrm{~V}\right)$ measurements respectively. The neutral salt spray studies confirmed the enhanced protection of DABA functionalised coatings which is proposed to result from the formation of smaller uniformly distributed particles of zirconia during the hydrolysis and condensation process thus providing a greater degree of thermal stability to the polymer network. AFM confirmed that the use of other ligands, such as acac, may result in the formation of the larger sized particles and thus a less compact polymer network facilitating the ingress of electrolyte to promote corrosion.

\section{Acknowledgments}

The authors would like to thank Enterprise Ireland for financial support through the Applied Research Enhancement (ARE) Programme and Dr. Luke O'Neil of the Focas Institute for AFM assistance.

\section{References}

[1] J. Zhao, L. Xia, A. Sehgal, D. Lu, R.L. McCreery, G.S. Frankel, Surf. Coat. Technol. 140 (2001) 51.

[2] T.L. Metroke, J.S. Gandhi, A. Apblett, Prog. Org. Coat. 50 (2004) 23.

[3] N.N. Voevodin, N.T. Grebasch, W.S. Soto, F.E. Arnold, M.S. Donley, Surf. Coat. Technol. 140 (2001) 16.

[4] R.L. Twite, G.P. Bierwagen, Prog. Org. Coat. 33 (1998) 91.

[5] I. Jerman, A.S. Vuk, M. Kozelj, B. Orel, J. Kovec, Langmuir 24 (2008) 5029.

[6] M.L. Zheludkevich, I. Miranda Salvado, M.G.S. Ferreira, J. Mater. Chem. 15 (2005) 5099.

[7] J. Livage, M. Henry, C. Sanchez, Prog. Solid State Chem. 288 (1988) 259.

[8] C.J. Brinker, G. Scherrer, Sol-gel Science: the Physics and Chemistry of Sol-Gel Processing, Academic Press, San Diego, CA, 1990.

[9] L.L. Hench, J.K. West, Chem. Rev. 90 (1990) 33.

[10] M. Guglielmi, J. Sol-Gel Sci. Technol. 8 (1997) 443.

[11] C. Sanchez, B. Julian, P. Belleville, M. Popall, J. Mater. Chem. 15 (2005) 3559.

[12] Sanchez, Romero (Eds), Functional Hybrid Materials, Wiley-VCH, Weinheim, ISBN-13: 978-3-527-30484-4.

[13] R.L. Parkhill, E.T. Knobbe, M.S. Donley, Prog. Org. Coat. 41 (2001) 261.

[14] H. Krug, F. Teillantes, P.W. Oliviers, H. Schmidt, Proc. SPIE1758, , 1992, p. 448.

[15] M. Khobaib, L.B. Reynolds, M.S. Donley, Surf. Coat. Technol. 140 (2001) 16.

[16] N. Voevodin, C. Jeffcoate, L. Simon, M. Khobaib, M.S. Donley, Surf. Coat. Technol. 140 (2001) 29.

[17] N.N. Voevodin, N.T. Grebasch, W.S. Soto, L.S. Kasten, J.T. Grant, F.E. Arnold, M.S Donley, Prog. Org. Coat. 41 (2001) 287.

[18] N.N. Voevodin, N.T. Grebasch, W.S. Soto, F.E. Arnold, M.S. Donley, Surf. Coat Technol. 140 (2001) 24.

[19] M.S. Donley, R.A. Mantz, A.N. Khramov, V.N. Balbyshev, L.S. Kasten, D.J. Gaspar, Prog. Org. Coat. 47 (2003) 401.

[20] L.S. Kasten, V.N. Balbyshev, M.S. Donley, Prog. Org. Coat. 47 (2003) 214.

[21] A.N. Khramov, V.N. Balbyshev, N.N. Voevodin, M.S. Donley, Prog. Org. Coat. 47 (2003) 401.

[22] A.N. Khramov, N.N. Voevodin, V.N. Balbyshev, M.S. Donley, Thin Solid Films 447 (2004) 549.

[23] A.N. Khramov, N.N. Voevodin, V.N. Balbyshev, R.A. Mantz, Thin Solid Films 483 (2005) 191.

[24] M.L. Zheludkevich, R. Serra, M.F. Montemor, M.G.S. Ferreira, Electrochem. Commun. 7 (2005) 836.

[25] M.L. Zheludkevich, K.A. Yasakau, S.K. Poznyak, M.G.S. Ferreira, Corros. Sci. 47 (2005) 3368.

[26] D.G. Shchukin, M. Zheludkevich, K. Yasakau, S. Lamaka, M.G.S. Ferreira, H. Mohwal, Adv. Mater. 18 (2006) 1672.

[27] M.F. Montemor, W. Trabelsi, M. Zheludevich, M.G.S. Ferreira, Prog. Org. Coat. 57 (2006) 67.

[28] S.K. Poznyak, M.L. Zheludkevich, D. Raps, F. Gammel, K.A. Yasakau, M.G.S. Ferreira Prog. Org. Coat. 62 (2008) 226.

[29] M. Chatry, M. Henry, M. In, C. Sanchez, J. Livage, J. Sol-Gel Sci. Technol., 1, 1994 p. 233.

[30] H. Hayashi, H. Suzuki, S. Kaneko, J. Sol-Gel Sci. Technol. 12 (1998) 87.

[31] P.C. Rajath Varma, J. Colreavy, J. Cassidy, M. Oubaha, C. McDonagh, B. Duffy, Prog. Org. Coat. 66 (2009) 406-411.

[32] M. Oubaha, P. Etienne, S. Calas, R. Sempere, J.M. Nedelec, Y. Moreau, J. Non-Cryst Solids 351 (2005) 2122.

[33] ASTM B117, Annual Book of ASTM Standards, Philadelphia, USA, 1997.

[34] M.F. Montemor, W. Trabelsi, M. Zheludevich, M.G.S. Ferreira, Prog. Org. Coat. 57 (2006) 67. 
[35] M.L. Zheludkevich, K.A. Yasakau, S.K. Poznyak, M.G.S. Ferreira, Corros. Sci. 47 (2005) 3368.

[36] F.X. Perrin, V. Nguyen, J.L. Vernet, J. Sol-Gel Sci. Technol. 28 (2003) 205.

[37] D. Hoebbel, T. Reinert, H. Schmidt, E. Arpac J. Sol-Gel Sci. Techn. 10 (1997) 115

[38] Z. Weihua, Z. Gaoyang, C. Zhiming, Mat. Sci. Eng. B 99 (2003) 168.

[39] J.R. Macdonald (Ed.), Impedance Spectroscopy Emphasising Solid Materials and Systems, Wiley/Interscience, New York, 1987.
[40] Q. Le Thu, G.P. Bierwagen, S. Touzain, Prog. Org. Coat. 42 (2001) 179.

[41] V. Palanivel, D. Zhu, W.J. van Ooij, Presentation at The Workshop on Nanoscale Approaches to Multifunctional Coatings, Keystone, CO, August 12-16, 2002.

42] P.C. Rajath Varma, B. Duffy, J. Cassidy, Surf. Coat. Technol. 204 (2009) 277.

[43] V. Barranco, S. Feliu Jr., S. Feliu, Corros. Sci. 46 (2004) 2203.

[44] J. Tafel, Z. Phys. Chem. 50 (1905) 641. 